\title{
NOTAS SOBRE MURILO MENDES, PIERRE JEAN JOUVE E A TRADIÇÃO CRISTÃ FRANCESA
}

\author{
Pablo Simpson
}

Em primeiro lugar, gostaria de indicar que venho retornando ao estudo de Murilo Mendes depois de uma peregrinação um tanto quanto excêntrica pelo que chamei de "tradição cristã francesa". Na verdade, refiro-me a um conjunto de poetas franceses, muitos deles convertidos ao catolicismo no início do século XX, durante uma voga de conversões mapeada por inúmeros críticos, como Frédéric Gugelot (1998). São conversões "em massa" - Gugelot contabiliza em torno de 6oo intelectuais franceses - que resultarão em "narrativas de conversão", para muitos desses escritores que compartilhariam a ideia de uma decadência geral à qual só a fé religiosa poderia se opor. Conversões que se produziram, como se sabe, num meio em vias de descristianização ou de secularização após a separação da Igreja e do Estado em 1905 na França. (Cf. POULAT, 2005) Refiro-me a poetas como Paul Claudel, Francis Jammes, Max Jacob, Pierre Reverdy, todos eles convertidos em circunstâncias por vezes curiosas, como no caso de Reverdy, que abandonaria posteriormente o catolicismo por não considerá-lo suficientemente exigente, embora permanecesse morando próximo à abadia de Solesmes. Ou de Max Jacob, que vê uma aparição do Cristo na parede de seu quarto depois de voltar da Biblioteca Nacional. 
Refiro-me, igualmente, a um conjunto de críticos franceses que estiveram próximos desses poetas, alguns deles também convertidos, e que foram lidos no Brasil durante o período modernista, como Jacques Maritain, Henri Bremond e Emmanuel Mounier. Lidos, por assim dizer, indiscriminadamente, tanto pelo grupo que Mário de Andrade chamou de poetas essencialistas e que talvez pudéssemos aproximar da revista modernista Festa - poetas como Murilo Araújo, Cecília Meirelles, Henriqueta Lisboa, dentre outros -, tanto por outro grupo, no qual Mário (ANDRADE, 1991, p. 15) incluía a si próprio, e que caracterizou como um grupo pouco afeito à ideia de um "humano geral". É sempre bom lembrar, aliás, que o curso sobre a noção de poesia pura do abade Henri Bremond - tão retomado recentemente pela crítica francesa sobre os gêneros literários na modernidade, pelo crítico Dominique Combe, por exemplo (1989) - foi acompanhado por Oswald de Andrade em sua temporada parisiense. E que Jacques Maritain esteve, várias vezes, no centro da reflexão de Alceu Amoroso Lima.

Percorri, portanto, algumas dessas preocupações tramadas aqui e ali por essa "tradição", que ponho entre aspas para não parecer que há apenas afinidades entre esses poetas e críticos, como se se tratasse de um movimento como os da vanguarda. São preocupações todas elas complexas na medida em que propõem uma imbricação entre um elemento conceitual e o engajamento religioso, e que indico rapidamente, sem aprofundar ${ }^{1}$. A primeira delas com a ideia de paisagem, por exemplo, como indicaria Michel Collot (1989, p. 41): "epifania precária de um sagrado que não se livra senão para retirar-se”. Paisagem que oscilaria entre uma "crise da paisagem", na confrontação desses poetas com uma espécie de inacessibilidade do horizonte, e a proposição de um sublime, vacilação dos limites entre o eu e o não eu, com toda a sua potência ética. A segunda preocupação, com a noção de símbolo. Contra a ideia de certa precariedade, haveria o desejo de fazer coincidir realidade sensível e representação, em vez da fuga incessante e indireta da alegoria. A terceira preocupação, com a noção de experiência mística como fruto da emoção poética, como se houvesse entre elas uma diferença apenas de grau. Mesmo Roger Bastide, leitor de Henri Bremond, transitaria entre essas duas noções em seus estudos sobre a poesia afro-brasileira. (Cf. SIMPSON, 2009, pp. 33-43) A quarta preocupação, com a ideia de

1 Parte dessas preocupações foram apresentadas no ensaio "Diálogos entre la poesía cristiana francesa y brasileña en el siglo XX”. In G. Cariello et alli (Org.) Tramos y Tramas III. Culturas, lenguas, literaturas e interdisciplina. Argentina: Labor de Editor, 2012. 
confiança como uma espécie de resposta a uma dimensão fragmentada do "eu" na modernidade e que viria acompanhada pela proposição de um "eu" estabelecido a partir de um enraizamento ou pertencimento ontológico - confiança restabelecida também através da pertença a uma comunidade religiosa, contra a maldição do poeta solitário moderno. Finalmente, com a ideia central de conversão: mudança das convicções, mudança do olhar, e que fez com que vários desses poetas renegassem uma parte da própria obra ou a reorganizassem na perspectiva dessa conversão. Assim fará o poeta Patrice de La Tour du Pin, que Jorge de Lima dizia ser um de seus prediletos, ao reunir, no fim da vida, três grandes tomos de sua poesia: o primeiro deles dedicado ao encontro do poeta consigo mesmo, o segundo do poeta "diante dos outros", o terceiro "diante de Deus". Pierre Jean Jouve, por sua vez, poeta sobre o qual me deterei um pouco mais, incluirá no início de sua obra poética, organizada também no fim da vida, um longo Paraíso perdido, situando a obra posterior sob o signo da queda.

Volto a Murilo Mendes por um caminho mais particular. Durante minha pesquisa sobre essa tradição francesa, dois diálogos entre poetas franceses e brasileiros me pareceram particularmente pertinentes, por afinidades que inicialmente eram mais de ordem musical, no sentido da música das palavras, para confirmar-se posteriormente com a presença de alguns temas recorrentes. O primeiro deles, que tive a oportunidade de aprofundar, entre o poeta francês Max Jacob e Mário de Andrade, em torno da representação do arlequim e da noção de artesanato (SIMPSON, 2011, pp. 107-127). O segundo, cuja investigação ainda hesito em fazer avançar, entre Murilo Mendes e Pierre Jean Jouve.

Hesito por algumas razões. A principal delas é que ainda não tive tempo de ir a Juiz de Fora para consultar a biblioteca de Murilo. Na verdade, pensei no diálogo entre ambos enquanto traduzia a poesia de Jouve para uma antologia da poesia cristã francesa publicada pela Editora da Unifesp², não o considerei como central para a poesia de Murilo, sobretudo em função de um dado importante de sua poesia que não existe em Jouve, assim como não existe na grande maioria dos poetas cristãos franceses que traduzi e com os quais o poeta brasileiro

2 O Rumor dos cortejos: antologia da poesia cristã francesa do século XX. São Paulo: Unifesp, 2012. 
se relacionou: o humor. Foi só mais recentemente, assim, que resolvi consultar a página web da biblioteca de Murilo, para descobrir nela, com alguma surpresa, 27 livros de Jouve, além de dois estudos de René Micha sobre a sua poesia, o que faz dela, muito provavelmente, o principal acervo da obra do poeta francês no Brasil. É um acervo tanto mais impressionante se levarmos em consideração que ele é maior do que o de autores franceses próximos de Murilo, como é o caso de Paul Claudel, para ficarmos entre os católicos, ou de André Breton, para ficarmos com os surrealistas, e se considerarmos que a obra de Jouve não é tão grande. Na verdade, Murilo reuniu algumas primeiras edições, como uma edição rara de Le Paradis Perdu de 1929, às quais somou edições posteriores. Evidentemente, não sei até que ponto a consulta desse acervo pode ser produtiva. No caso de Mário de Andrade, por exemplo, havia em sua biblioteca inúmeros livros de Max Jacob, mas só um deles, de fato, com anotações. De todo modo, o acervo assinala o interesse de Murilo por esse poeta relativamente desconhecido do grande público francês, e que começou a ser relido nos últimos anos graças ao esforço crítico de Yves Bonnefoy e Jean Starobinski, que ajudaram na organização dos dois volumes de suas obras completas.

Murilo Mendes, além disso, dedicou a Pierre Jean Jouve um papier e um "retrato-relâmpago", este último incluído na segunda série, de 1973 e 1974, embora tenha sido escrito em 1971. Do panorama de poetas convertidos ao catolicismo na França, Jouve é o único que ocupa as páginas desses livros de homenagens (não vou entrar no mérito da breve e conturbada conversão de Jean Cocteau, que também é mencionado por Murilo). No panorama poético francês, em geral, são os poetas surrealistas ou próximos ao surrealismo que são convocados, alguns com reticências: André Breton, de quem Murilo sente "atração e repulsa”, e René Char, que parece "terrivelmente distante". Jouve, aliás, é mencionado mais na sua relação com o surrealismo do que com a poesia religiosa.

Gostaria de citar alguns trechos do "retrato-relâmpago", porque ajudam a situar rapidamente o interesse de Murilo:

O autor mais que ilustre de Les Noces, Sueur de Sang, Matière Céleste, recebe-me (1953) no seu apartamento de Alésia, bairro parisiense durante muito tempo preferido pelos artistas.

[...] Jouve forma sua cultura e funda sua linguagem sob o quádruplo signo de Nerval, Baudelaire, Rimbaud e Mallarmé, aos quais tem sido sempre fiel.

[...] Nos anos que precederam a Segunda Guerra Mundial Jouve escreveu, sob o título Inconscient, Spiritualité et Catastrophe, o prefácio histórico de um de seus livros maiores, Sueur de Sang, interessando-se de perto pela 
psicanálise (estudara a obra de Freud, este Jules Verne da psicologia atual), aplica-a de certo modo no livro citado (e em outros); aprofunda o drama da humanidade, cujo destino é desde o início presidido pelos irmãos gêmeos: Eros e Morte. Com uma tal agudeza profética, que nesses textos já sentimos aproximar-se os passos terroristas de 1939. Essa aplicação de propostas freudianas à poesia assume grande importância, completando de certo modo a invenção surrealista. [...] Para Jouve o inconsciente é "motor de poesia". Impossível separar o sexual do espiritual. Mesmo o canto religioso provém de zonas subterrâneas.

[...] Na última vez que o vi em sua casa, Jouve pôs na eletrola um disco da Flauta Mágica. Atrai-me particularmente o trecho em que Pamina e Tamino cantam: "Marchamos pela magia da música, sem medo através das trevas e da morte". Assim Mozart interfere na amizade de dois poetas que distinguem nele um exorcizador dos poderes demoníacos, um intérprete das forças totalitárias de Eros [...].

Os trechos, como se pode perceber, condensam uma variedade de questões, todas elas difíceis de serem abordadas brevemente: a dimensão da catástrofe e da morte, a ideia de um canto religioso que viria das zonas profundas do inconsciente, mas também a de uma música regeneradora capaz de "exorcizar os poderes demoníacos", a de Mozart.

Há ainda esse lugar bem "surrealista" do inconsciente como "motor de poesia", ao qual Jouve opunha a presença de um mundo sensível (que é também o mundo da encarnação), desde o poema "Monde sensible". No prefácio de Sueur de Sang, falaria mesmo de um abismo doloroso do homem que, com o seu narcisismo ferido, passaria a ter acesso a essas forças desconhecidas:

Os poetas que trabalharam desde Rimbaud a liberar a poesia do racional sabem muito bem [...] que encontraram no inconsciente, ou ao menos no pensamento tanto quanto possível influenciado pelo inconsciente, a antiga e a nova fonte, e que se aproximaram com isso de um alvo novo para o mondo. Pois somos, como diz Freud, massas de inconsciente ligeiramente elucidadas na superfície pela luz do sol. (JOUVE, 1987, p. 198)

Pode-se dizer, portanto, que Murilo está atento à complexa oscilação em Jouve entre mística do corpo, da profundidade das pulsões sexuais, por exemplo, e mística de Deus. Atento a esse caminho duplo em direção às pulsões eróticas e ao sagrado, dividido entre o que se poderia caracterizar como transcendência baixa, desdobramento do mito teológico da origem, e transcendência alta da conversão religiosa: o fogo da carne e o branco do céu. (STAROBINSKI, apud Jouve, op. cit., p. lxxvi)

Essa fusão de contrários, por assim dizer, resultou numa preocupação em Jouve com a noção de símbolo. É ela que gostaria de desenvolver 
nesta rapidamente, ainda que isso permaneça um tanto abstrato. Jouve chamou de símbolo o estado psíquico de aglutinação representado pela poesia. Composição musical, apelo a uma harmonia como divinação ou sublimação, liberando o "eu" das forças inconscientes, retirando-o do caos, que chamaria também de "catástrofe". A poesia seria menos uma espécie de abertura ao invisível e ao desconhecido - infinito representado de maneira finita - do que um gesto de composição, conforme sugerido a partir da poética de Baudelaire. Talvez pudéssemos ver nele o que Davi Arrigucci Jr. chamou de "integridade da forma" em Murilo Mendes, articulação poética que busca a unidade e a experiência de um mundo desencontrado, numa construção poética a partir das ruínas. (ARRIGUCCI JR., 1997, p. 80) "Reconquista sobre o paraíso perdido", como diria Murilo: "nós procuramos na poesia o que foi perdido pelo erro e pelo atraso dos homens". (Apud MOURA, 1995, p. 141)

Insisto sobre essa ideia de composição musical - e lembro do interesse comum de ambos por Mozart - porque em Jouve tanto quanto em Murilo o resultado é, contraditoriamente, a presença de versos imelódicos e inarmônicos, como observou José Guilherme Merquior (Merquior que falou do olhar ciclópico de Jouve no prefácio às obras completas de Murilo). (MERQUIOR, 1994) Peço licença para citar um trecho de uma carta de Manuel Bandeira a Mário de Andrade, de 1931, que aponta justamente para uma falta de ritmo em Murilo, como se não bastasse a falta de melodia e de harmonia. Cito o comentário de Bandeira:

Só que achei é que o Murilo em alguns versos, como no penúltimo, parece não ser poeta no sentido propriamente técnico ou melhor de ouvido, entendendose por poeta o sujeito que tem o sentido imediato do ritmo. [...] Nunca vi versos regulares do Murilo e certas fraquezas de ritmo em poemas como este último é que me fazem pensar que ele seria incapaz de passar incólume na antiga Caixa do Malho. [periódico humorístico que circulou entre 1902 e 1954] (ANDRADE e BANDEIRA, 2001, p. 499)

É o mesmo que diria Claudel, com um tanto mais de maldade, sobre a poesia de Jouve:

Não, mil vezes não, não gosto de P. J. Jouve e os versos (!) que você me enviou não mudam a minha opinião. Faz mais de vinte anos que esse infeliz que é o perfeito miserável me envia suas "poesias" que vão direto para a lixeira. Nunca vi nele rastro de gosto, de inteligência ou de dom. O que é mais desgraçado é a completa ausência de ouvido. [...] O acento tônico do qual depende o resto do verso está sempre mal posicionado. (LEUWERS, 2004, p. 150) 
Em Jouve, de fato, para atingir o que chamaria de frase musical, há uma dicção pouco pontuada que espaça as palavras, desloca acentos rítmicos. Jouve utiliza, assim, em vários momentos, frases nominais; em frases verbais, inverte verbo e sujeito, distanciando-os na elocução do poema. Recolho um trecho do "retrato-relâmpago" de Murilo, atento a isso que chamou de trabalho da poesia, que se refletiria numa organização sintática distinta:

[...] Jouve estuda a psiconeurose do mundo, atento aos signos da catástrofe produzida pelo inconsciente. A transposição destas análises para o plano da criação poética custou-lhe um árduo trabalho, o de fletir audaciosamente a sintaxe.

Nesse sentido, é importante assinalar que o mergulho nas profundezas espirituais em Jouve não resultará nem no automatismo da imaginação surrealista, tampouco fará com que a forma poética preserve o caráter mais discursivo - mais melódico, por assim dizer - de parte da poesia simbolista, que estará, de algum modo, presente na tradição de poesia religiosa francesa: a cadência do alexandrino que ouvimos em Paul Claudel, por exemplo, e mesmo nas gravações que Reverdy fez de sua própria poesia. Talvez porque em Jouve - mas também em Murilo - a música em jogo seja aquela de Alban Berg, sobre a qual escreveu em Wozzeck ou le Nouvel Opéra (Paris, Plon, 1953) ou no poema "Fin de Wozzeck" de Mélodrame. Música de uma "audácia livre e dura e estrangeira", como assinalou na segunda parte do poema "Tombeau de Berg":

Et vous linéaments merveilleux anxieux

Qui dites la passion infinie à la terre

Et tous les dons du ciel à nouveau traversés

Par une audace libre et dure et étrangère

[E vós lineamentos maravilhosos ansiosos

Que dizeis a paixão infinita à terra

E todos os dons do céu novamente atravessados

Por uma audácia livre e dura e estrangeira] (JOUVE, 1987, p. 928)

Música que é, preferencialmente, em Murilo, combate, dissonância: "As duas antigas praias que se defrontam, / Melodia e harmonia", no poema "Exegese" de Parábola. (MENDES, 2002, p. 549) Ou em "O filho pródigo" dos Sonetos brancos: 
Para outros armaste o teu festim:

E da tua música só vem agora

O soluço da terra, dissonante. (Idem, p. 445)

A noção de composição musical em Jouve vem acompanhada, no entanto, como já se indicou, justamente da noção de símbolo, que traria consigo a ideia de aglutinação. Embora José Guilherme Merquior tenha observado na poesia de Murilo Mendes a separação entre um mundo fantástico, de caráter alegórico, e uma dimensão do "visionário" que chamaria de simbólica, (MERQUIOR, 1965) em Murilo tenho a impressão de que a noção mais evocada é a de alegoria, com a qual intitulou dois poemas, nos livros Poemas e Sonetos brancos. Alegoria com todos os seus enigmas, signos, lutas, máquinas, "palavras sangrentas" no poema homônimo de Sonetos brancos.

Ainda aqui, não sei o quanto poderia ser produtivo transitar por essa essa seara um tanto quanto esquemática e cheia de contradições: símbolo versus alegoria, embora me pareça que ela possa assinalar algumas diferenças dentro dessas duas concepções de poesia religiosa tão equidistantes do surrealismo e da tradição dos poetas católicos. Num mundo em que a presença da guerra e a temática das ruínas parece fundir-se, em Murilo Mendes tanto quanto em Pierre Jean Jouve, a um imaginário dos anjos - cito Jouve, "Em baixo do bairro de esmeralda e de ácido sujo / Esses deslizamentos são anjos / Os crimes retirando-se sobre as costas dos muros", no poema "Guerre"3, (1987, p. 84) e Murilo Mendes, no poema "O visionário": "À luz do dia foi que eu vi fantasmas / Nas vastas praças do país do amor, / E também anjos no meio-dia intenso / Que me consolam da visão do mal" -; nesse mundo em ruínas, tenho a impressão de que em Murilo a catástrofe é mais exterior, e que o mundo interior é a possibilidade de reconstruir a religião, o que Jouve descartaria. Reconstruir a religião, por assim dizer, através da poesia, como indicou em $O$ Discípulo de Emaús, na ideia de que a poesia deve ser "um dos aspectos principais da nova pedagogia que visa formar o homem", o "homem integral", como em Maritain. (MENDES, 2002, p. 831)

Ao mesmo tempo, há uma vertigem do tempo presente em Murilo que não reencontro em Jouve, para um eu frequentemente à espera do "espírito poderoso que fundirá os tempos", como no poema "História" de As metamorfoses:

3 "En bas du quartier d'émeraude et d'acier sale / Ces glissements sont des anges / Les crimes se retirant sur le dos des murs." 
Nos jardins cobertos de rosas migradoras

E nos berços onde dormem crianças com fuzis.

O espírito poderoso que fundirá os tempos

Espera, impaciente, nos átrios celestes. (MENDES, 2002, p. 59)

"Eu" que, diante da vertigem, produzida pelas enumerações dos poemas de Murilo - num tempo que é, por vezes, um "galope" em "Aproximação do terror": "Ninguém ampara o cavaleiro do mundo delirante", diria em "Overmundo" -, aguardaria uma espécie de reconciliação apocalíptica, como em "Poema presente" (MENDES, p. 413 e p. 401):

Sombras pedindo corpos

Esperam desde o dilúvio

O sopro de um puro espírito

Separam a luz da luz.

Apesar disso, tal vertigem não alcançará jamais o tom muitas vezes melancólico de Jouve. É a ele que gostaria de convidar com a leitura da segunda parte do poema "Adeus" de Jouve, do livro Mélodrame de 1957:

Longas linhas de tristeza e de névoa

Abrem de todo lado esta planície infinita

Onde os montes se evaporam depois retomam

Em alturas que não toca mais o olhar:

Lá onde chegamos, dá tua mão,

Depois aos salgueiros mais arrasados que nossos silêncios

Na grama do verão que destroem teus pés

Diz uma palavra sem razão profere um verdadeiro poema,

Deixa que eu acaricie enfim os teus cabelos mortos

Pois a morte vem rolando longe para nós os seus tambores,

Deixa que eu retoque inteiramente teu corpo

No seu vale ou praia extrema flor do tempo

Que eu dobre um joelho diante de teu erro moreno

Tua beleza teu perfume defunto perto da partida

Adorando teu erro teu vício e teu capricho

Adorando teu abismo negro sem firmamento.

Deixa ó já perdida, e que eu te abençoe

Pelos males pelos quais me ensinaste o amor

Por todas as palavras com que me ensinaste o canto. (JOUVE, 1987, p. 976) 
104 - Remate de Males 32.1

\section{REFERÊNCIAS BIBLIOGRÁFICAS}

ANDRADE, M. de. Querida Henriqueta, cartas de Mário de Andrade a Henriqueta Lisboa. Rio de Janeiro: José Olympio, 1991.

ANDRADE, Mário de e BANDEIRA, Manuel. Correspondência, organizada por Marcos Antonio de Moraes. São Paulo: Edusp, 2001.

ARRIGUCCI JR., D. "O cacto e as ruínas". In Arquitetura da memória, a poesia entre outras artes. São Paulo: Duas Cidades, 1997.

COLLOT, Michel. La Pensée moderne et la structure d'horizon. Puf, 1989.

COMBE, Dominique. Poésie et récit: une autre rhétorique des genres. Éditions José Corti, 1989.

GUGELOT, Frédéric. Conversion des intellectuels au catholicisme en France: 1885-1935. CNRS Éditions, 1998.

JOUVE, Pierre Jean. Euvre I, texte établi et présenté par Jean Starobinski, avec une note de Yves Bonnefoy et pour les textes inédits la collaboration de Catherine Jouve et René Micha. Mercure de France, 1987.

LEUWERS, Daniel. "Pierre Jean Jouve et Paul Claudel”. In Pierre Jean Jouve, revue Europe, $82^{\mathrm{e}}$ année, n. 907-908, nov-dez. 2004.

MENDES, Murilo. Poesia completa e prosa. Rio de Janeiro: Aguilar, 2002.

MERQUIOR, José Guilherme. "Murilo Mendes ou a poética do visionário”. In Razão do poema, ensaios de crítica e estética. Rio de Janeiro: Civilização Brasileira, 1965.

. "Notas para uma muriloscopia”. In Mendes, M. Poesia completa e prosa. Rio de Janeiro: Nova Aguilar, 1994.

MOURA, Murilo. Murilo Mendes: a poesia como totalidade. São Paulo: Giordano, 1995.

POULAT, Émile. La Question religieuse et ses turbulences au XXe siècle: trois générations de catholiques en France. Berg International, 2005.

SIMPSON, Pablo. “Deslizar nas ruas, entre Mário de Andrade e Max Jacob”. In Revista do Instituto de Estudos Brasileiros, v. 53, 2011.

.Fontes longínquas que jorram: sobre Roger Bastide e o conceito de mística". In Terra Roxa e Outras Terras, v. 17, 2009.

STAROBINSKI, Jean. "Le feu de la chair et la blancheur du ciel”. In Jouve, P. J. EEuvre I, op. cit. 